\title{
PERAN BIDAN SEBAGAI MOTIVATOR DALAM PROMOSI KESEHATAN PADA IBU HAMIL
}

\author{
Eka Rati Astuti ${ }^{1}$, Liya Lugita Sari ${ }^{2}$ \\ ${ }^{1,2)}$ Akademi Kebidanan Manna \\ liyalugitasari@gmail.com
}

\begin{abstract}
ABSTRAK
Promosi dalam bidang kesehatan adalah cara pemerintah mengelola Sistem Kesehatan Nasional. Peran bidan dalam peningkatan peran serta masyarakat pada bidang kesehatan dilakukan secara perorangan, kelompok, dan komunitas yang berada di masyarakat. Tujuan penelitian yang dilakukan untuk melihat gambaran peran bidan sebagai motivator dalam promosi kesehatan pada ibu hamil di area kerja Puskesmas Tungkal. Penelitian ini menggunakan metode deskriptif jenis survei. Sampel dalam penelitian ini adalah bidan di wilayah kerja Puskesmas Tungkal yang berjumlah 24 orang. Instrumen yang digunakan adalah checklist. Analisis data dilakukan secara univariat dengan memakai nilai T. Hasil penelitian diperoleh nilai standar deviasi hasil penelitian ialah 0,28 dan nilai mean 33,00. Dapat disimpulkan bahwa peran bidan sebagai motivator dalam promosi kesehatan pada ibu hamil di wilayah kerja Puskesmas Tungkal pada tahun 2020 termasuk kategori baik.
\end{abstract}

Kata kunci : motivator, peran bidan, promosi kesehatan

\begin{abstract}
Promotion in the health sector is the Government's way of managing the National Health System. The role of midwives increasing community participation in the health sector is carried out individually, in groups, and communities in society. The purpose of this research was to describe the role of midwives as a motivator in health promotion for pregnant women in the work area of Tungkal Health Centre. This study used a descriptive type of survey method. The sample in this study was 24 midwives in the work area of Tungkal Health Centre. The instrument used was a checklist. Data analysis performed univariately using $T$ score formula. The results showed that the standard deviation of the research results was 0.28 , and the mean value was 33.00. After finding the T score and comparing the mean value with the T score, 19 people (79.2\%) had a proper role and five people (20.8\%) have fewer roles in the category of respondents. It can conclude that the role of midwives as a motivator in health promotion for pregnant women in the Tungkal Health Centre in 2020 is in a proper category.
\end{abstract}

Keywords: health promotion, motivator, role of the midwife 


\section{PENDAHULUAN}

Angka Kematian Ibu (AKI) telah mengalami penurunan dari tahun 2015 sebanyak 248/100.000 kelahiran hidup menjadi 226/100.000 kelahiran hidup, namun data ini belum mencapai target yang ditetapkan oleh pemerintah. Walaupun sudah banyak upaya yang dilakukan oleh pemerintah untuk dapat menurunkan angka kematian ibu, tetapi tetap saja terdapat kendala terkait penurunan kematian ibu ini (Kementerian Kesehatan RI, 2018).

Data dari Dinas Kesehatan Provinsi Bengkulu didapatkan bahwa masih tingginya AKI di Provinsi Bengkulu tahun 2018 yaitu sebesar 111 per 100.000 kelahiran hidup. Kematian Ibu tertinggi terjadi di Bengkulu Selatan yaitu tercatat 1 orang kematian Ibu (Bengkulu, 2019).

Kematian ibu 75\% disebabkan oleh perdarahan (perdarahan postpartum), infeksi pascapersalinan, hipertensi selama kehamilan (preeklamsia dan eklamsia), komplikasi selama persalinan dan aborsi yang tidak aman. Penyebab lain $(25 \%)$ disebabkan karena infeksi lain seperti malaria atau penyakit kronis (jantung dan diabetes) (WHO, 2019).

Bidan sebagai motivator sangat berperan bagi kesehatan ibu hamil maupun bayi yang dikandungnya. Hal ini mengacu pada Keputusan Menkes RI No.900/Menkes/SK/VII/2002 mengenai registrasi dan praktik bidan. Bidan memberikan promosi kesehatan terhadap ibu hamil dan keluarga untuk memelihara kesehatan dan mempersiapkan pemberian ASI esklusif (Astuti et al., 2017).

Bidan sebagai motivator dalam promosi kesehatan pada ibu hamil memberikan promosi kesehatan sejak ibu hamil tersebut datang pertama kali ke bidan. Puskesmas Tungkal Kabupaten Bengkulu Selatan telah melaksanakan program promosi kesehatan, akan tetapi program tersebut belum dilaksanakan secara konsisten dan berkesinambungan. Secara langsung bidan di wilayah Puskesmas Tungkal telah melaksanakan promosi pada ibu hamil. Hal tersebut dilihat dari beberapa orang bidan melaksanakan pendidikan kesehatan kepada ibu-ibu hamil, namun promosi kesehatan ini belum dievaluasi secara konsisten oleh Dinas Kesehatan Kabupaten Bengkulu Selatan, dimana tidak adanya data yang pasti terhadap pelaksanaan promosi tersebut (Selatan, 2019).

Terdapat 24 orang bidan yang bekerja di Puskesmas Tungkal pada bulan Oktober 2019, terdiri dari 16 bidan yang bekerja di Puskesmas Tungkal dan 8 yang bekerja sebagai bidan desa. Bidan melakukan promosi kesehatan dengan memberikan motivasi kepada ibu hamil mengenai perilaku hidup bersih, pola makan yang baik, dan pemeriksaan kesehatan yang teratur, untuk menyiapkan kehamilan dan persalinan yang normal (Selatan, 2020).

Penelitian ini bertujuan untuk mengetahui "Gambaran Peran Bidan Sebagai Motivator Dalam Promosi Kesehatan pada Ibu Hamil di Wilayah Kerja Puskesmas Tungkal Kabupaten Bengkulu Selatan”.

\section{METODOLOGI}

Penelitian ini menggunakan metode deskriptif jenis survei. Penelitian ini menggambarkan peran bidan sebagai motivator dalam promosi kesehatan pada ibu hamil di wilayah kerja Puskesmas Tungkal Kabupaten Bengkulu Selatan yang dilaksanakan pada bulan April 2020.

Populasi dalam penelitian ini adalah bidan di wiayah kerja Puskesmas Tungkal yang berjumlah 24 orang. Sampel dalam penelitian ini menggunakan teknik total sampling.

Instrumen yang digunakan adalah checklist. Hasil ukur dikatakan baik apabila nilai $\mathrm{T} \geq$ mean dan dikatakan kurang apabila nilai $\mathrm{T}<$ mean. Teknik analisis data menggunakan analisis univariat. 
HASIL

Checklist terdiri dari 10 pernyataan meliputi 7 pernyataan positif dan 3 pernyataan negatif. Checklist berisi tentang pernyataan dengan tema asuhan sayang ibu dan SOP yang harus dilakukan oleh bidan saat memotivasi ibu hamil saat promsi kesehatan.

Hasil penelitian didapatkan untuk kalimat positif $(+)$ apabila responden yang menjawab sangat setuju diberikan skor 4 , setuju diberikan skor 3, tidak setuju diberikan skor 2, sangat tidak setuju diberikan skor 1. Sedangkan untuk kalimat negatif (-) responden yang menjawab sangat tidak setuju diberikan skor 4, tidak setuju diberikan skor 3, setuju diberikan skor 2, sangat setuju diberikan skor 1 .

Tabel 1.Hasil Ukur Motivasi Bidan

\begin{tabular}{|c|c|c|c|c|c|}
\hline Responden & $\begin{array}{c}\text { Jumlah } \\
\text { Skor }\end{array}$ & $\begin{array}{c}\text { Standar } \\
\text { Deviasi }\end{array}$ & Mean & T skor & Hasil Ukur \\
\hline 1 & 34 & 0,28 & 33,00 & 85,55 & Baik \\
\hline 2 & 35 & 0,28 & 33,00 & 121,10 & Baik \\
\hline 3 & 33 & 0,28 & 33,00 & 50,00 & Baik \\
\hline 4 & 33 & 0,28 & 33,00 & 50,00 & Baik \\
\hline 5 & 33 & 0,28 & 33,00 & 50,00 & Baik \\
\hline 6 & 32 & 0,28 & 33,00 & 14,45 & Kurang \\
\hline 7 & 33 & 0,28 & 33,00 & 50,00 & Baik \\
\hline 8 & 32 & 0,28 & 33,00 & 14,45 & Kurang \\
\hline 9 & 33 & 0,28 & 33,00 & 50,00 & Baik \\
\hline 10 & 33 & 0,28 & 33,00 & 50,00 & Baik \\
\hline 11 & 33 & 0,28 & 33,00 & 50,00 & Baik \\
\hline 12 & 32 & 0,28 & 33,00 & 14,45 & Kurang \\
\hline 13 & 34 & 0,28 & 33,00 & 85,55 & Baik \\
\hline 14 & 33 & 0,28 & 33,00 & 50,00 & Baik \\
\hline 15 & 25 & 0,28 & 33,00 & $-234,39$ & Kurang \\
\hline 16 & 34 & 0,28 & 33,00 & 85,55 & Baik \\
\hline 17 & 33 & 0,28 & 33,00 & 50,00 & Baik \\
\hline 18 & 25 & 0,28 & 33,00 & $-234,39$ & Kurang \\
\hline 19 & 35 & 0,28 & 33,00 & 121,10 & Baik \\
\hline 20 & 35 & 0,28 & 33,00 & 121,10 & Baik \\
\hline 21 & 34 & 0,28 & 33,00 & 85,55 & Baik \\
\hline 22 & 34 & 0,28 & 33,00 & 85,55 & Baik \\
\hline 23 & 36 & 0,28 & 33,00 & 156,65 & Baik \\
\hline 24 & 38 & 0,28 & 33,00 & 227,75 & Baik \\
\hline
\end{tabular}

Berdasarkan tabel 1 dapat dilihat bahwa nilai standar deviasi hasil penelitian yaitu 0,28 dan mean 33,00. Selanjutnya nilai T skor yang didapatkan dibandingkan dengan nilai mean dengan aturan baik jika nilai $\mathrm{T} \geq$ nilai mean atau rata-rata (x) dan kurang jika nilai $\mathrm{T}<$ nilai mean atau rata-rata. Selanjutnya dapat dilihat distribusi frekuensi hasil ukur gambaran bidan sebagai motivator dalam promosi kesehatan di Wilayah Kerja Puskesmas Tungkal Kabupaten Bengkulu 
Selatan tahun 2020 sebagai berikut:

Tabel 2. Distribusi Frekuensi Peran Bidan

\begin{tabular}{clcc}
\hline No & Peran Bidan & f & \% \\
\hline 1 & Baik & 19 & 79,2 \\
2 & Kurang & 5 & 20,8 \\
\hline & Jumlah & $\mathbf{2 4}$ & $\mathbf{1 0 0}$ \\
\hline
\end{tabular}

Berdasarkan tabel 2 dapat dilihat bahwa sebesar 79,2 \% menggambarkan peran bidan yang baik sebagai motivator dalam promosi kesehatan di Wilayah Kerja Puskesmas Tungkal pada tahun 2020

\section{PEMBAHASAN}

Berdasarkan hasil penelitian diperoleh hasil nilai checklist responden dengan jumlah skor tertinggi 38 dan T skor 227,75, dan dinyatakan bidan sudah berperan dengan baik sedangkan nilai checklist responden terendah dengan jumlah skor 25 dan T skor -234,39, dan dinyatakan bidan berperan kurang. Dari hasil analisis penelitian sehingga diperoleh nilai rata-rata 33,00 dan nilai standar deviasi hasil penelitian yaitu 0,28 , kemudian dilihat dari distribusi frekuensi hasil ukurpenelitian pada tabel4.3, responden termasuk kategori sudah berperan baik sebanyak 19 orang dengan persentase $79,2 \%$ dan kurang sebanyak 5 orang dengan persentase $20,8 \%$. Sehingga di simpulkan bahwa peran bidan diwilayah kerja puskesmas tungkal sudah termasuk baik dilihat dari nilai $\mathrm{T} \geq$ Mean yaitu dengan hasil persentase $79,2 \%$.

Salah satu strategi untuk meningkatkan kemampuan masyarakat dalam hal Pengetahuan, sikap dan praktik untuk dapat berperilaku sehat yaitu dengan cara melakukan promosi kesehatan melalui pembelajaran bersama masyarakat. Tujuan utama promosi kesehatan ini setelah diberikan promosi masyarakat dapat menolong dirinya sendiri serta dapat mengembangkan sumber daya yang ada dilingkungan masyarakat sesuai dengan kondisi setempat serta harus didukung pula oleh kebijakan publik yang berlaku dan berwawasan kesehatan (Hutagaol, 2018).

Ujung tombak pelayanan kesehatan di masyarakat adalah Puskesmas dimana Puskesmas bertugas untuk meningkatkan derajat kesehatan masyarakat. Puskesmas bukan hanya menjadi tempat untuk pengobatan dan rehabilitatif saja tetapi harus lebih meningkatkan tindakan promotif dan preventif oleh sebab itu pemerintah sudah menggalakkan kegiatan promosi kesehatan menjadi kegiatan yang wajib di Puskesmas. Salah satu upaya promosi untuk mengenali masalah kesehatan, mencegah dan menanggulanginya yang dapat dilakukan puskesmas dalam memberdayakan masyarakat disekitar puskesmas dan pengunjung yaitu dengan melakukan Perilaku Hidup Bersih dan Sehat (PHBS) (Selatan, 2020).

Merupakantanggungjawabbersamauntuk melakukan promosi kesehatan. Tenaga kesehatan maupun pegawai di puskesmas diharapkan dapat menjadi teladan dalam menerapkan perilaku hidup Bersih dan Sehat, untuk pengunjung serta masyarakat di wilayah kerja Puskesmas dapat menerapkan perilaku hidup bersih dan sehat melalui kader kesehatan yang ada di masyarakat. Upaya promosi kesehatan bukan hanya menjadi tanggung masyarakat dan puskesmas saja tetapi juga menjadi tanggung jawab pemerintah kabupaten/kota dan sektor terkait untuk dapat memfasilitasi puskesmas untuk dapat melakukan promosi kesehatan. (Astuti et al., 2017).

Dampak positif promosi kesehatan bagi ibu hamil yaitu ibu hamil dapat mengetahui betapa pentingnya mengikuti posyandu, agar dapat melihat dan memantau tumbuh kembang anak, ibu hamil dapat mengetahui betapa pentingnya perawatan payudara untuk persiapan pemberian ASI Eksklusif (Setiawati et al., 2015).

Motivasi Bidan dapat meningkatkan keteguhan hati ibu hamil untuk memiliki 
motivasi kuat dalam melakukan antenatal care yang lengkap dalam upaya pencegahan Anemia selama kehamilan, dapat memelihara kesehatan kehamilan yang ideal (Fitrayani et al., 2016).

Ibu hamil dapat mengetahui cara menjaga kehamilan dengan baik, dapat mengetahui ciri-ciri kehamilan berisiko tinggi dan cara mengatasinya, dapat mengetahui tanda-tanda bahaya kehamilan, mengetahui, menyadari dan mengkondisikan emosional selama kehamilan,mengetahui bagaimana tanda-tanda persalinan, tenaga kesehatan khususnya bidan dapat memberikan informasi pada Ibu hamil mengenai tanda awal kehamilan pemeriksaan rutin serta dapat memberikan penyuluhan untuk dapat menjaga nutrisi yang tepat, pola istirahat yang baik, cara merawat Kebersihan diri memantau keadaan ibu hamil dan calon bayinya serta dapat menurunkan Angka kematian Ibu dan Bayi dan membantu program pemerintah (Sumardino \& Sunarto, 2016).

Berdasarkan seluruh jawaban responden mengenai peran bidan sebagai motivasi dalam promosi kesehatan pada ibu hamil dapat dilihat bahwa hampir seluruh responden setuju dengan adanya promosi kesehatan yang dilakukan oleh bidan, dengan adanya motivasi yang diberikan bidan maka cenderung akan meningkatkan informasi ibu hamil tentang masa kehamilan (Septikasari, 2018) serupa penelitian oleh (Tombokan et al., 2016), yang menunjukan hasil bahwa sesudah mendapatkan motivasi dan promosi kesehatan, pengetahuan ibu hamil dapat meningkat sehingga ibu hamil mengetahui tentang tanda bahaya kehamilan. Penelitian oleh (Sumardino \& Sunarto, 2016) yang menunjukan bahwa sesudah mendapatkan motivasi dan promosi kesehatan, pengetahuan ibu hamil dapat meningkat sehingga ibu hamil dapat mengetahui tentang antenatal care dengan baik, penelitian oleh (Hutagaol, 2018) yang menunjukan hasil bahwa sesudah mendapatkan motivasi dan promosi kesehatan, pengetahuan ibu hamil tentang kesiapan birth preparedness terhadap kesiapan ibu hamil trimester III dapat meningkat.

\section{SIMPULAN DAN SARAN}

Simpulan yang dapat diambil yaitu peran bidan sebagai motivator dalam promosi kesehatan termasuk kategori baik $(79,2 \%)$ di wilayah kerja Puskesmas Tungkal tahun 2020.

\section{Saran}

1. Bidan agar dapat selalu melakukan promosi kesehatan untuk ibu hamil terkhususnya di wilayah kerja Puskesmas Tungkal.

2. Bidan harus selalu memotivasi ibu hamil untuk mengikuti kegiatan promosi kesehatan yang diadakan pihak Puskesmas Tungkal dalam rangka peningkatan kesehatan ibu dan anak.

Bidan harus bisa memberikan pemahaman dengan mudah kepada ibu hamil melalui berbagai media, misalnya gambar sederhana atau video simulasi

3. Bidan harus terus menerus menjadi motivator baik secara mandiri dengan melakukan konseling atau dengan melakukan kunjungan rumah masing-masing ibu hamil, kolaborasi dan juga ketergantungan dengan mengadakan promosi kesehatan yang diadakan di wilayah puskesmas, balai desa, atau bisa bersamaan dengan waktu diadakannya posyandu dengan melibatkan tenaga kesehatan lainnya seperti dokter spesialis kandungan.

\section{DAFTAR PUSTAKA}

Astuti, L. P., Prasida, D. W., \& Wardhani, P. K. (2017). Peran dan Fungsi Bidan Dalam Pelaksanaan Informed Consent Pada Kegawat Daruratan Obstetri di Puskesmas. Jurnal Kebidanan, IX(2), 101-120.

Bengkulu, D. P. (2019). Profil Kesehatan Provinsi Bengkulu Tahun 2018. Dinas Kesehatan 
Provinsi Bengkulu.

Fitrayani, Suryati, \& Faranti, R. M. (2016).

Penyebab Rendahnya Kelengkapan

Kunjungan Antenatal Care Ibu Hamil di wilayah Kerja Puskesmas Pegambiran. Kesehatan Masyarakat Andalas, 10(1), 101-107.

Hutagaol, I. octaviana. (2018). Peran Promosi Kesehatan Oleh Bidan Dalam Persiapan Birth Preparedness terhadap Kesiapan Ibu Hamil Trimester III di Puskesmas Bulili dan Hikobuli Kota Palu. Excelent Midwifery Journal, 1(2), 66-72.

Kementerian Kesehatan RI. (2018). Profil Kesehatan Indonesia tahun 2017.

Kementerian Kesehatan.

Selatan, D. K. B. (2019). Profil Kesehatan Kabupaten Bengkulu Selatan Tahun 2018. Dinas Kesehatan Kabupaten Bengkulu Selatan.

Selatan, D. K. B. (2020). Profil Puskesmas Tungkal Tahun 2019. Dinas Kesehatan Kabupaten Bengkulu Selatan.
Septikasari, M. (2018). Peran Bidan Dalam Asi Eksklusife di Kabupaten Cilacap tahun 2018. Aisiyah:Jurnal Ilmu Kesehatan, 3(2), 109-113.

Setiawati, E., Muktar, \& Maslani, N. (2015). Hubungan Sikap dan peran Bidan terhadap Program Pemberian Asi Ekskusif di Wilayah Kerja Puskesmas Jambu Buru Kabupaten Banjar. Skala Kesehatan, 6(1), 1-7.

Sumardino, \& Sunarto. (2016). Promosi kesehatan Dengan Buku KIA Terhadap Peningkatan Pengetahuan Ibu Hamil dan Antenatal Care di Puskesmas Ceper Klaten tahun 2011. Jurnal Keperawatan Global, 1(1), 16-22.

Tombokan, S., Bokau, J. N., \& Tuju, S. O. (2016). Pengaruh Promosi Kesehatan Tentang Tanda Bahaya Kehamilan Terhadap Peningkatan Pengetahuan Ibu Hamil. Jurnlah Ilmiah Bidan, 4(1), 38-43.

WHO. (2019). Maternal Mortality. https://www. who.int/news-room/fact-sheets/detail/ maternal-mortality 